\title{
Aula de campo para ensino e aprendizagem de Geociências a partir de atividades de reconhecimento do sambaqui do rio Salinas (ES)
}

Field class for teaching and learning Geoscience from activities to ReCognize the sambaqui of the Salinas River (ES)

\author{
Deovalr Monteiro Cesar \\ Professor de Ciências do ensino fundamental, Sistema de Ensino Municipal de Anchieta, ES, Brasil. \\ E-MALL: MONTEIROCSAR@gMALl.COM
}

\begin{abstract}
Scientific literacy, in relation to school activities, uses field classes as a pedagogical methodology, seeking to develop scientific knowledge in the science teaching-learning process. Thus, the objective of this research was to undertake a field class in the Salinas river midden, considered a non-formal space of teaching, based on activities developed along knowledge generating themes. This is a qualitative research, of the "participant observation" type, which included the participation of $7^{\text {th }}$ year students of "Professor Zuleika Flores da Purificação" Elementary School, at Anchieta, Espírito Santo, Brazil. As a result, we point out that the totality of data collected by the groups could characterize some aspects of the midden, revealing pedagogical potentialities. We can affirm that from the point of view of the teaching-learning process, the results demonstrate advances in the scientific literacy of the participating student group.
\end{abstract}

Resumo: A alfabetização científica, no que diz respeito às atividades escolares, utiliza-se da aula de campo como metodologia pedagógica, com vistas ao desenvolvimento de saberes científicos no processo de ensino-aprendizagem de Ciências. Desta maneira, o objetivo da pesquisa foi empreender uma aula de campo no sambaqui do rio Salinas, considerado espaço não-formal de ensino, a partir de atividades desenvolvidas em temas geradores de conhecimentos. Trata-se de uma pesquisa qualitativa, com procedimentos do tipo "observação participante", que contou com a participação de estudantes do $7^{0}$ ano da Escola Municipal de Ensino Fundamental "Professora Zuleika Flores da Purificação", Anchieta, Espírito Santo, Brasil. Como resultados, apontamos que a totalidade dos dados coletados pelos grupos conseguiu caracterizar alguns aspectos do sambaqui, revelando potencialidades pedagógicas. Podemos afirmar que, do ponto de vista do processo de ensino-aprendizagem, os resultados demonstram avanços na alfabetização científica do grupo de estudantes participante.
Citation/Citação: Cesar, D. M. (2020). Aula de campo para ensino e aprendizagem de Geociências a partir de atividades de reconhecimento do sambaqui do rio Salinas (ES). Terræ Didatica, 16, 1-13, e020047. doi: 10.20396/ td.v16i0.8661195

Keywords: Non-formal space. Geoscience teaching. Scientific literacy.

Palavras-chave: Espaço não-formal. Ensino de Geociências. Alfabetização científica.

\section{Manuscript/Manuscrito:}

Received/Recebido: 17/08/2020

Revised/Corrigido: 24/09/2020

Accepted/Aceito: 24/11/2020

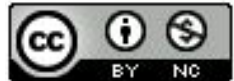

\section{Introdução}

A iniciação científica no ensino fundamental, vista como um processo de ensino-aprendizagem, no âmbito da educação formal, tem sido imprescindível para os avanços no ensino de Ciências nas últimas décadas no Brasil e no mundo e vem ganhando força nos debates da comunidade acadêmica, no que diz respeito ao conceito de alfabetização científica com vistas à atividade escolar e à pesquisa.

A finalidade da Alfabetização Científica (AC), de acordo com Chassot (2016), é formar cidadãos autônomos e aptos a participarem das tomadas de decisão de forma crítica, compreendendo os processos da ciência e tecnologia no mundo em que vivem.

A partir do conceito de AC, Sasseron \& Carvalho (2011), ao longo do tempo, desenvolvem uma revisão bibliográfica com o propósito de identificar as habilidades necessárias para que um indivíduo possa ser considerado alfabetizado cientificamente. As autoras apresentam eixos estruturantes que apontam linhas propositivas para o planejamento e o desenvolvimento de práticas pedagógicas que promovam processos de alfabetização científica.

Desta maneira, a aula de campo constitui-se, por meio da relação entre o objeto, o pesquisador, o estudante e o espaço pesquisado. A cultura da aprendizagem que constitui os sujeitos do processo também é originada pelas ações dos sujeitos com seus pares e com o mundo ao seu redor. As aulas de campo podem favorecer avanços na alfabetização científica dos seus participantes, já que um dos objetivos da alfabetização científica, de acordo com Chassot (2003), seria construir o encorajamento do cidadão para que ele tenha a oportunidade de 
discutir questões envolvendo o ambiente em que vive. As ações com caráter de investigação, não menos que o espaço não-formal na sua totalidade, são determinantes no processo de ensino e aprendizagem, tendo em vista as correlações entre o ambiente, seus meios e os seus praticantes.

A investigação no ensino de ciências seguiu o caminho de promover a alfabetização científica, empregando práticas pedagógicas no ambiente externo ao espaço da sala de aula, propiciando o contato dos estudantes com a realidade do ambiente natural, onde se constituem os conceitos estudados. Os espaços não-formais têm sido bastante utilizados pelos professores, como uma forma de complementar e dinamizar o ensino.

Os sambaquis, cenário da pesquisa, são sítios arqueológicos do período pré-colonial brasileiro, em cujo entorno viviam os primeiros brasileiros, de maneira organizada e produziam culturas, tal como o próprio sambaqui, que se configura como um cenário constituído a partir das múltiplas dimensões de saberes científicos e culturais. $\mathrm{O}$ espaço, o tempo e a atividade pedagógica se inter-relacionam na pesquisa ensejando as condições para o desenvolvimento de aprendizagens colaborativas na construção de conhecimentos. Tais discussões abrem espaço para o conjunto de questões que nortearam a realização da pesquisa, as quais passamos a elencar, seguidas dos objetivos fixados.

Quais as potencialidades pedagógicas dos sambaquis para o ensino de Ciências, com vistas à alfabetização científica? De que forma o ensino por meio de temas geradores de conhecimentos em um sítio arqueológico do tipo sambaqui, pode contribuir para os avanços na alfabetização científica dos estudantes? De que maneira a aula de campo pode favorecer uma abordagem dos conteúdos escolares de Ciências?

Investigar este espaço não-formal com múltiplas possibilidades de desenvolvimento de metodologias pedagógicas, no ensino de Ciências, como a aula de campo, é fundamental para o desenvolvimento dos avanços da alfabetização científica. $\mathrm{O}$ planejamento e o conhecimento do ambiente pelo professor são fundamentais para o desenvolvimento da aula de campo.

Desta forma, os temas geradores são pedagogicamente propícios, uma vez que o estudante entra em contato com evidências e manifestações culturais e ambientais produzindo conhecimentos.

Entre estas possibilidades, o tópico de malacologia no ensino de Ciências foi adotado como o principal tema gerador para contextualizar os aspectos naturais do sambaqui, uma vez que sua constituição estrutural é composta pela deposição de conchas de moluscos.

Em resumo, foi desenvolvida uma sequência de atividades, dentro das quais constava uma aula de campo, dividida em três momentos, e nesse transcurso procuramos observar os avanços dos alunos no que diz respeito à alfabetização científica. Para desenvolver o projeto de pesquisa no cotidiano da escola, organizou-se o Projeto de Extensão Escolar "Ciências no Sambaqui do rio Salinas".

\section{Os sambaquis como espaço não-formal de ensino}

Sambaquis são sítios arqueológicos monticulares distribuídos por toda a costa brasileira, ocupando principalmente zonas de tons ecológicos cambiantes, como regiões lagunares e áreas recortadas de baías e ilhas (Deblasis, 2007). Foram construídos por grupos de pescadores-coletores chamados sambaquieiros, os quais não eram índios, apesar de a palavra sambaqui ter origem tupi (tamba significa conchas e ki, amontoado) (Gaspar, 2000). Eram hominídeos pertencentes à espécie "sapiens sapiens" e se alimentavam de peixes e mariscos, frutos e sementes, além de alguns mamíferos. Nos sambaquis que construíam, eles sepultavam os seus mortos, ocupando o território brasileiro há aproximadamente 4.000 anos antes do presente (AP). Foram extintos algum tempo após a chegada dos ceramistas, que eram grupos indígenas de organização social tribal e exímios guerreiros. A extinção se deu por volta de 1500 anos AP.

Construídos tanto em planícies quanto em encostas, diretamente na areia ou sobre o embasamento rochoso, os sambaquis ocorrem desde o Rio Grande do Sul até o Amapá, os quais estão localizados junto a corpos d'água como lagoas, estuários, mangues, marismas e ao Oceano Atlântico. Contudo, em algumas regiões do Brasil, como Amazônia, São Paulo e norte de Santa Catarina, existem também sambaquis localizados próximos aos rios, chamados sambaquis fluviais (Cardoso, 2019).

Os sambaquis chamaram atenção dos pesquisadores pelos vestígios de sepultamentos. A grande quantidade de esqueletos encontrados no seu interior fez emergir diversas pesquisas ao longo dos anos focadas nos estudos dos ossos e das práticas culturais desses grupos, buscando compreender aspectos da demografia, das atividades físicas, das situações de violência, da mobilidade e dos hábitos alimentares (Cardoso, 2019). 
Estudos arqueológicos comprovam que os peixes exerciam papel importante na dieta dos povos sambaquieiros, tendo em vista a diversidade de vestígios ictiológicos nos sambaquis. Entretanto, apesar de uma economia essencialmente baseada na pesca e na exploração de produtos marinhos, há indícios de que os sambaquieiros praticavam manejo de vegetais, incluindo espécies de tubérculos e árvores frutíferas (Scheel-Ybert, 2001).

No trabalho intitulado "Paleoambientes e paleoetnologia de populações sambaquieiras do sudeste do Estado do Rio de Janeiro", Sheel-Ylbert (1999) destaca que os sambaquis da Região dos Lagos ocuparam um ambiente caracterizado basicamente pela interface de três associações vegetais: a restinga, o manguezal e formações florestais como a mata seca, característica da região de Cabo Frio e a mata atlântica. Para Cardoso (2019), a grande dispersão de sambaquis pela costa brasileira corresponde também à variação de formas de viver e de se organizar por parte dos grupos que os construíram.

Tendo em vista a existência de vasta pesquisa arqueológica, a partir desta relação de autores citados, percebe-se o quanto é necessário desenvolver práticas pedagógicas nos sambaquis, uma vez que é notório, também, a escassez de publicações acerca do desenvolvimento de aulas de campo nestes sítios arqueológicos, sobretudo, no ensino básico.

As poucas práticas pedagógicas descritas em anais e revistas no contexto da pesquisa e do ensino de Ciências como espaço não-formal de ensino levam-nos a concluir que os sambaquis são utilizados pedagogicamente para a formação docente. Acerca da relação dos sambaquis, suas potencialidades e a aula de campo, pode-se discernir o quanto é necessário o incentivo e o investimento, no que se refere às práticas pedagógicas no contexto da escola de nível fundamental.

Usar os espaços não-formais para ensinar conceitos e conhecimentos é contribuir para formação de cidadãos conscientes do que está a sua volta. Os sítios arqueológicos construídos pelos povos sambaquieiros representam construções antrópicas, arquitetadas a partir dos elementos naturais e muito estudadas e discutidas na arqueologia, desde o início do período imperial.

Os sambaquis do estado do Espírito Santo são em número considerável, estendendo-se de norte a sul da costa capixaba. Do ponto de vista das pesquisas arqueológicas e antropológicas, é regular o material publicado, acerca destes sítios pré-coloniais. De acordo com o Instituto do Patri- mônio Histórico e Artístico Nacional (IPHAN), existem cadastrados dezesseis sítios arqueológicos do tipo sambaqui em todo o estado do Espírito Santo, Brasil.

Um dos sambaquis localizados no município de Anchieta, na região sul capixaba foi tomado e caracterizado como espaço não-formal, ambiente propício ao desenvolvimento das práticas pedagógicas propostas na investigação, aos avanços na alfabetização científica do grupo participante e em último caso para o ensino de ciência.

\section{A malacologia como tema gerador no ensino de Ciências}

A pesquisa propõe o desenvolvimento crítico dos sujeitos participantes, uma vez que, por meio de instrumentos próprios, considera as relações com seus pares e com o espaço não-formal de ensino. Desta maneira, de acordo com Freire (1987), durante a investigação, os estudantes atuam como construtores de possibilidades para a práxis, com suas transformações, e com vistas à permanente liberdade no processo de ensino-aprendizagem de Ciências.

O tópico de malacologia no ensino de Ciências, como dito anteriormente, foi adotado como o principal tema gerador de conhecimento para contextualizar os aspectos naturais do sambaqui, uma vez que sua constituição estrutural é composta pela deposição de conchas de moluscos.

A malacologia é a área que se reserva aos estudos sobre os moluscos. O filo Mollusca é considerado um dos maiores do reino animal, do ponto de vista da diversidade biológica e dos modos de vida adaptados aos diversos ecossistemas terrestre ou aquático. Sua ocorrência é observada desde as fossas abissais até as mais altas montanhas ou, ainda, das geleiras polares até as regiões desérticas (Colley et al., 2012). Constituem o segundo maior grupo zoológico conhecido pela ciência, sendo representado por aproximadamente 100 mil espécies viventes e 70 mil espécies fósseis.

A partir deste breve perfil histórico acerca da malacologia, é importante dizer que um dos objetivos específicos propostos na pesquisa é caracterizar o sítio arqueológico estudado, os quais são as evidências principais da malacofauna dos sambaquis.

Desta forma, os temas geradores devem ser compreendidos a partir das conversas entre as partes, sujeito e mundo, que nos direciona para o entendimento da articulação entres os saberes do 
ser humano inacabado e o mundo em acabamento. Se a programação educativa é dialógica, isto significa o direito que também têm os educadores e educandos de participar dela, incluindo temas não sugeridos. A estes, por sua função, chamamos "tema dobradiça" (Freire, 2011), os quais significam temas que articulam vários outros temas ou contém as relações entre conteúdos e a visão de mundo dos sujeitos participantes do processo de ensino-aprendizagem.

Portanto, os temas geradores e seus desdobramentos, colocam em leitura as condições que relacionam ambiente, seus tempos, espaços e sujeitos, promovendo ações e retroações, e assim a transformação real dos sujeitos em face do conhecimento.

\section{A aula de campo e a alfabetização científica}

O processo de AC decorrente da estratégia permite a tomada de decisão consciente, por parte do cidadão, uma vez que ele atua e transforma a natureza em que está inserido.

Segundo Chassot (2016), interrogações como: por que ensinar Ciências? Por que (re)temos os estudantes por tantos anos na escola? Essas são questões fundamentais para a agenda educacional brasileira, sobretudo, no que diz respeito à escola pública, representando as bases das transformações necessárias, com relação às responsabilidades e habilidades relativas ao processo de alfabetização.

A nossa responsabilidade maior ao ensinar Ciências é procurar que nossos alunos e alunas se transformem, com o ensino que fazemos, em homens e mulheres mais críticos. Sonhamos que, com o nosso fazer educação, os estudantes possam tornar-se agentes de transformações - para melhor - do mundo em que vivemos (Chassot, 2016). Corroborando a premissa, Sasseron \& Carvalho (2011) apresentam eixos estruturantes que apontam linhas propositivas para o planejamento e o desenvolvimento de práticas pedagógicas que promovam processos de AC.

As autoras consideram os seguintes eixos estruturantes da AC: $\mathrm{O}$ primeiro refere-se à "compreensão básica de termos, conhecimentos e conceitos científicos fundamentais". Tendo em vista o público-alvo, este eixo concentra-se na possibilidade de trabalhar com os estudantes a construção de conhecimentos científicos necessários até o momento para que lhes seja possível aplicá-los em situações diversas e de modo apropriado. O segundo eixo preocupa-se com a "compreensão da natureza das ciências e dos fatores éticos e políticos que circundam sua prática". Com vistas à sala de aula do ensino fundamental, esse eixo fornece-nos subsídios para que o caráter humano e social inerente às investigações científicas seja colocado em pauta. Concebe, pois, a ideia de ciência como um corpo de conhecimentos em constantes transformações, que vão sendo construídos por meio de processo de aquisição e análise de dados, síntese e decodificação de resultados que originam os saberes. $\mathrm{O}$ terceiro eixo estruturante da AC "Compreende o entendimento das relações existentes entre ciência, tecnologia, sociedade e ambiente". Trata-se, pois, da identificação de que estas esferas se encontram mutuamente entrelaçadas e, desse modo, uma solução imediata para um problema em uma destas áreas pode representar, mais tarde, o aparecimento de um outro problema associado.

Conforme estes eixos estruturantes, os indicadores da alfabetização científica adotados foram adaptados ao contexto da pesquisa, de acordo com o espaço não-formal, os objetivos e a responsabilidade social da pesquisa, uma vez que as atividades desenvolvidas buscaram não alterar a paisagem do sítio arqueológico. Estes indicadores são algumas competências próprias das ciências e do fazer científico (Sasseron \& Carvalho, 2008).

Desta maneira, a partir dos dados constituídos pelas resoluções, discussões, divulgações e conclusões produzidas por meio de atividades participativas no ensino de ciências, os eixos estruturantes podem tornar-se compreensíveis do ponto de vista da atitude investigativa dos participantes, uma vez que sua participação no processo de ensino e aprendizagem de

Tabela 1. Os eixos estruturantes e os indicadores de AC adotados. Fonte: Adaptado de Sasseron \& Carvalho (2008)

\begin{tabular}{|c|c|}
\hline Eixos Estruturantes & Indicadores \\
\hline $\begin{array}{l}1^{\circ} \text { - Compreensão básica de termos, } \\
\text { conhecimentos e conceitos científicos } \\
\text { fundamentais }\end{array}$ & \multirow{3}{*}{$\begin{array}{l}\text { - Seriação de informação } \\
\text { - Organização de informação } \\
\text { - Classificação de informação } \\
\text { - Raciocínio lógico } \\
\text { - Raciocínio proporcional } \\
\text { - Levantamento de hipóteses } \\
\text { - Testes de hipóteses } \\
\text { - Justificativa } \\
\text { - Previsão } \\
\text { - Explicação }\end{array}$} \\
\hline $\begin{array}{l}2^{\circ} \text { - Compreensão da natureza das } \\
\text { ciências e dos fatores éticos e políticos } \\
\text { que circundam sua prática }\end{array}$ & \\
\hline $\begin{array}{l}3^{\circ} \text { - Compreensão e entendimento } \\
\text { das relações existentes entre ciência, } \\
\text { tecnologia, sociedade e meio-ambiente }\end{array}$ & \\
\hline
\end{tabular}


ciências é a premissa fundamental para o avanço da AC, por meio da aula de campo. A Tabela 1, elaborada a partir de Sasseron \& Carvalho (2008), apresenta os eixos estruturantes e os indicadores de AC adotados para análise dos dados correspondentes.

As aulas de campo classificam-se, de acordo com seu papel didático, em ilustrativa, indutiva, motivadora, formativa e investigativa, de onde decorrem seus objetivos, os métodos de ensino, os questionamentos acerca dos modelos científicos atuais, o processo ensino-aprendizagem na relação professor-aluno e finalmente a lógica predominante no processo de aprendizagem (Compiani \& Carneiro, 1993).

Os autores propõem que é preciso planejar a aula de campo a partir de uma série de objetivos, a saber: exercitar habilidades, adquirir ou exemplificar conhecimentos teóricos, coletar dados para análise e despertar atitudes, habilidades que podem ser praticadas em três características básicas na aula de campo: dirigida pelos professores, semidirigida com auxílio de guia ou monitor e a autodirigida, em que o aluno se orienta sozinho, a partir de observações prévias. As atividades de campo planejadas a partir dos papeis didáticos estabelecem condições dialógicas que potencializam o aprendizado, quando pautadas na colaboratividade entre os participantes da ação. Desta maneira, os objetivos e os métodos desencadeiam processos de ensino e aprendizagem que dialogam com os papeis didáticos da aula de campo e com a alfabetização científica, almejando melhorias no ensino de Ciências.

Os objetivos de ensino irão orientar cada parâmetro norteador, de maneira distinta, objetivando as premissas, as relações estabelecidas entre os participantes, os questionamentos e a lógica predominante no processo de ensino-aprendizagem como apresenta a Tabela 2.
O pré-campo é momento em que o professor organiza os conhecimentos curriculares, propõe a investigação de campo, seus objetivos, metodologias de coleta de dados, registros e análise. No campo, os estudantes devem ser capazes de pensar criticamente acerca dos fenômenos observados. Coleta, organização e análise de dados, a partir de métodos específicos são atividades complexas, que propiciam aos estudantes o desenvolvimento de um olhar questionador. O terceiro e último momento da aula de campo, o pós-campo, é importante para a construção dos saberes e dos conhecimentos desenvolvidos no campo. O pós-campo é o momento em que a aprendizagem aparece com ênfase, tendo em vista que os diálogos estabelecidos entre os sujeitos, o espaço e os objetivos da aula de campo ocorrem por meio da interação. Portanto, assim se configura a aula de campo como metodologia para esta pesquisa.

\section{Local da pesquisa}

O sambaqui do rio Salinas fica localizado na região do monumento turístico conhecido como "Ruínas do rio Salinas", na cidade de Anchieta, sul do estado do Espírito Santo, Brasil. Um dos principais aldeamentos construídos pelos jesuítas no Brasil está nas terras capixabas, cujo entorno é constituído de vestígios de ocupações pré-coloniais, como os sambaquis. Banhada por rios e pelo mar, Reritiba era como se chamava a atual cidade de Anchieta, fundada em 1569.

Atualmente, Anchieta possui uma população estimada em 29.263 habitantes, área de $411.898 \mathrm{Km}^{2}$, de acordo com os dados do Instituto Brasileiro de Geografia e Estatísticas (IBGE) no biênio 2018-2019. O município capixaba contém três distritos: Alto Pongal, Anchieta (Sede) e Jabaquara, e está localizado

Tabela 2. Os papeis didáticos da aula de campo e o grau de influência dos objetivos. Fonte: Adaptado de (Compiani \& Carneiro, 1993)

\begin{tabular}{c|c|c|c|c}
\hline $\begin{array}{c}\text { Categoria/ } \\
\text { papel }\end{array}$ & $\begin{array}{c}\text { Visão de } \\
\text { ensino }\end{array}$ & $\begin{array}{c}\text { Modelos } \\
\text { científicos } \\
\text { existentes }\end{array}$ & $\begin{array}{c}\text { Relação de ensino } \\
\text { aprendizagem }\end{array}$ & $\begin{array}{c}\text { Lógica } \\
\text { predominante }\end{array}$ \\
\hline Ilustrativa & Informativa & $\begin{array}{c}\text { São aceitos e } \\
\text { preservados }\end{array}$ & $\begin{array}{c}\text { Professor é o centro } \\
\text { Ensino dirigido }\end{array}$ & Da ciência \\
\hline Indutiva & $\begin{array}{c}\text { Informativa/ } \\
\text { Formativa }\end{array}$ & $\begin{array}{c}\text { São aceitos e } \\
\text { preservados }\end{array}$ & $\begin{array}{c}\text { Aluno é o centro. } \\
\text { Ensino dirigido/semi-dirigido }\end{array}$ & $\begin{array}{c}\text { Da ciência e do } \\
\text { aprendiz }\end{array}$ \\
\hline Motivadora & Formativa & $\begin{array}{c}\text { São aceitos e } \\
\text { preservados, em } \\
\text { grau variável. }\end{array}$ & $\begin{array}{c}\text { Aluno é o centro } \\
\text { Estudo não dirigido }\end{array}$ & Do aprendiz \\
\hline Treinadora & $\begin{array}{c}\text { Formativa/ } \\
\text { Informativa }\end{array}$ & $\begin{array}{c}\text { São aceitos e } \\
\text { preservados }\end{array}$ & $\begin{array}{c}\text { Equilíbrio } \\
\text { Ensino semi-dirigido }\end{array}$ & $\begin{array}{c}\text { Da ciência e às } \\
\text { vezes do aprendiz }\end{array}$ \\
\hline Investigativa & Formativa & $\begin{array}{c}\text { São aceitos, mas } \\
\text { questionados. }\end{array}$ & $\begin{array}{c}\text { Aluno é o centro } \\
\text { Ensino não dirigido }\end{array}$ & $\begin{array}{c}\text { Da ciência e do } \\
\text { aprendiz }\end{array}$ \\
\hline \hline
\end{tabular}




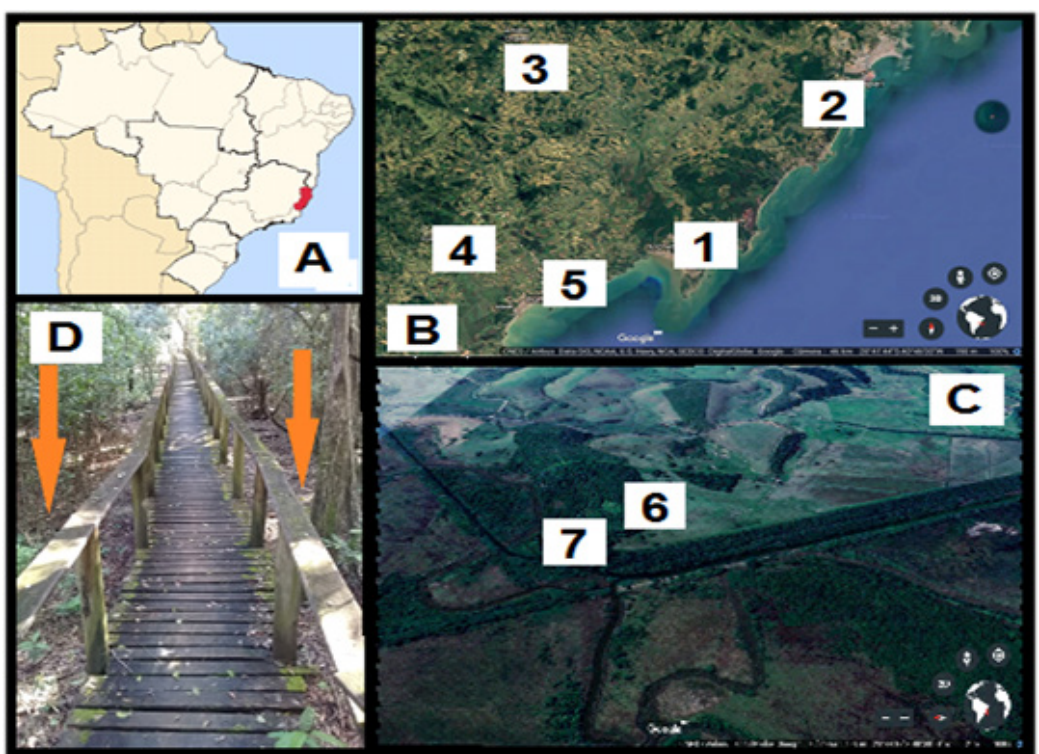

Figura 1. Local da pesquisa. Caracterização dos limites da área de estudo a partir de uma visão macroscópica, com a localização do Estado do Espírito Santo, chegando à visão mesoscópica, que corresponde ao local investigado (sentido horário). A) Localização geográfica do Estado do ES. B) Cidades limítrofes do município de Anchieta; 1. Anchieta Sede; 2. Guarapari; 3. Alfredo Chaves; 4. Iconha; 5. Piúma. C) 6. Ruínas do rio Salinas. 7. Região do sítio arqueológico do tipo sambaqui. D) Setas indicadoras da área de intervenção no sambaqui estudado (20 $44^{\prime} 47^{\circ} \mathrm{S}$ e $\left.40^{\circ} 39^{\prime} 16^{\circ} \mathrm{W}\right)$. Fonte: $\mathrm{O}$ autor na microrregião Sul. Apresenta clima superúmido e subquente, com média entre $15^{\circ} \mathrm{C}$ e $18^{\circ} \mathrm{C}$, relevo de serras e tabuleiros costeiros (Formação Barreiras) e vegetação de mata atlântica. A Figura 1 apresenta a região, o entorno e o local da pesquisa.

A região das ruínas do rio Salinas estão a dezenove metros acima do nível do mar atualmente e é protegida por lei ambiental do município de Anchieta. É classificada como Unidade de Conservação (UC), cuja responsabilidade pela proteção é da Secretaria de Meio Ambiente e Recursos Naturais (SEMAN). É considerado um dos pontos turísticos mais frequentados do município, com acesso por navegação pelos rios Benevente e Salinas e, por terra, por meio da estrada ES-146, próximo à comunidade de Goembê. O sambaqui do rio Salinas especificamente situa-se a oito metros do nível do mar atualmente, como mostra a Figura 2. previamente.
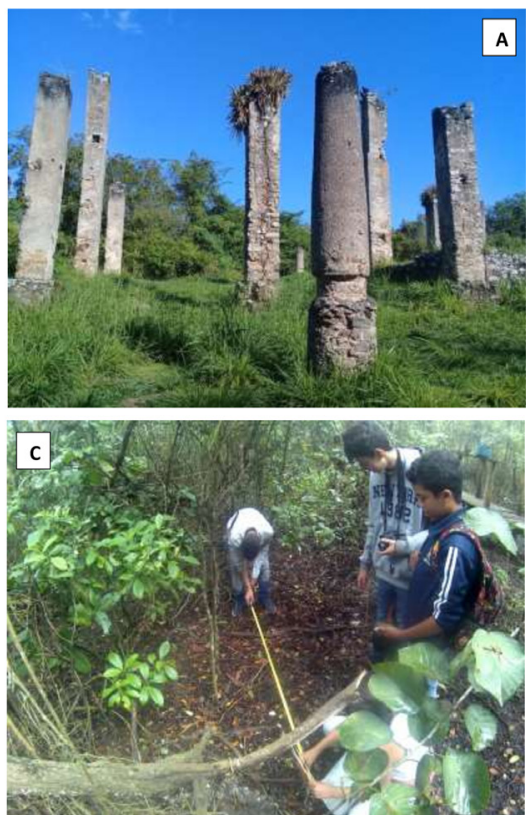

Como dito anteriormente, o sambaqui do rio Salinas se encontra em uma área recoberta pela vegetação de mata atlântica e caracterizada pelo ecossistema manguezal, onde as atividades da aula de campo foram desenvolvidas.

\section{Procedimentos metodológicos}

A aula de campo foi dividida em três etapas: o pré-campo, o campo e o pós-campo, as quais foram desenvolvidas sob a orientação do professor-pesquisador (PP). Foram adotados os procedimentos do tipo "observação participante", em acordo com Ludke \& André (1986) e os diálogos, transcritos dos áudios e vídeos gravados durante as etapas.

A Tabela 3 apresenta as atividades desenvolvidas na etapa pré-campo, que foi desenvolvida no ambiente escolar e na Casa da Cultura de Anchieta-ES, onde os conceitos fundamentais e as atividades de campo foram discutidos e treinados,
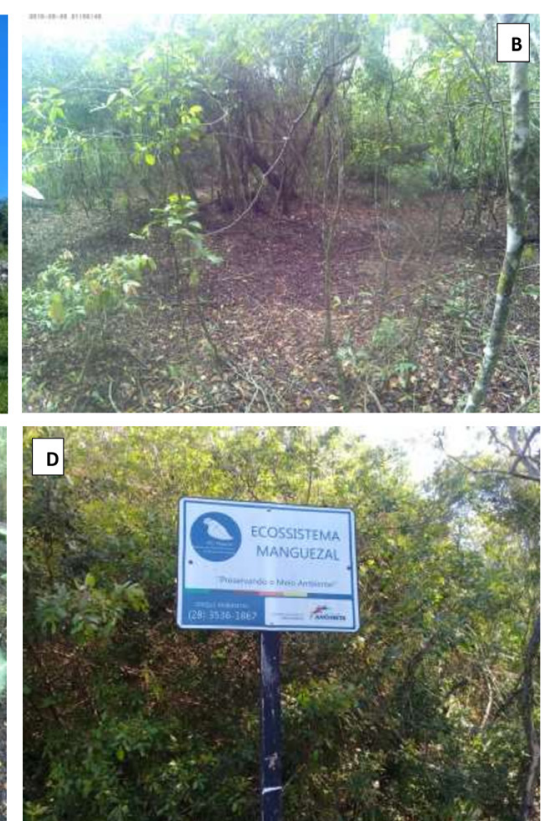

Figura 2. As ruínas e o sambaqui do rio Salinas. A) Ruínas. B) Sambaqui. C) Delimitação do quadrante. D) Identificação do ecossistema. Fonte: $\mathrm{O}$ autor

\begin{tabular}{c|c|c|c|c|c}
\hline (C) Terrae Didat. & Campinas, SP & v.16 & $1-13$ & $\mathrm{e} 020047$ & 2020 \\
\hline
\end{tabular}


Tabela 3. Planejamento da etapa pré-campo. Fonte: $\mathrm{O}$ autor

\begin{tabular}{|c|c|c|c|c|}
\hline $\begin{array}{l}\text { Aula } \\
\text { Dur. }\end{array}$ & Conteúdo & Objetivos & Atividade & Instrumento \\
\hline $2 \mathrm{~h}$ & $\begin{array}{l}\text { Evolução } \\
\text { Humana }\end{array}$ & $\begin{array}{l}\text { Situar os estudantes nos } \\
\text { tempos pretéritos da } \\
\text { evolução dos hominí- } \\
\text { deos. }\end{array}$ & $\begin{array}{l}\text { Áudio } \\
\text { visual }\end{array}$ & Vídeo \\
\hline $2 \mathrm{~h}$ & $\begin{array}{l}\text { Educação } \\
\text { Patrimonial }\end{array}$ & $\begin{array}{l}\text { Evidenciar aos estudan- } \\
\text { tes que os sambaquis } \\
\text { são patrimônio da hu- } \\
\text { manidade. }\end{array}$ & Palestra & $\begin{array}{l}\text { Comunicação } \\
\text { oral }\end{array}$ \\
\hline $2 \mathrm{~h}$ & $\begin{array}{l}\text { Os povos } \\
\text { pré-coloniais } \\
\text { do litoral } \\
\text { brasileiro }\end{array}$ & $\begin{array}{l}\text { Apresentar aos estudan- } \\
\text { tes a cultura dos povos } \\
\text { pré-coloniais, o am- } \\
\text { biente em que viviam e } \\
\text { seus hábitos. }\end{array}$ & $\begin{array}{l}\text { Áudio } \\
\text { visual }\end{array}$ & $\begin{array}{l}\text { Vídeo } \\
\text { Aplicativo } \\
\text { Power point }\end{array}$ \\
\hline $2 \mathrm{~h}$ & Seres vivos & $\begin{array}{l}\text { Conhecer características } \\
\text { peculiares das espécies } \\
\text { de moluscos que consti- } \\
\text { tuem om sambaqui. }\end{array}$ & $\begin{array}{l}\text { Oficina de } \\
\text { Malacologia }\end{array}$ & $\begin{array}{l}\text { Imagens, livro, } \\
\text { celular e cartão } \\
\text { escala. }\end{array}$ \\
\hline $2 \mathrm{~h}$ & $\begin{array}{l}\text { Informações } \\
\text { preliminares } \\
\text { para inter- } \\
\text { venção de } \\
\text { campo. } \\
\text { Coleta de } \\
\text { dados }\end{array}$ & $\begin{array}{l}\text { Caracterizar o local da } \\
\text { pesquisa. } \\
\text { Apresentar aos estudan- } \\
\text { tes os instrumentos de } \\
\text { coleta de dados. } \\
\text { Dividir e organizar os } \\
\text { grupos. } \\
\text { Aplicar questionário. }\end{array}$ & $\begin{array}{l}\text { Aula expo- } \\
\text { sitiva dialo- } \\
\text { gada }\end{array}$ & $\begin{array}{l}\text { Aplicativo } \\
\text { Power point } \\
\text { Roteiro de } \\
\text { campo } \\
\text { Diário de } \\
\text { campo } \\
\text { Celular } \\
\text { Trena } \\
\text { Questionário } \\
\text { estruturado. }\end{array}$ \\
\hline
\end{tabular}

é imprescindível na construção dos saberes científicos, as vivências pedagógicas em espaços não-formais de ensino.

Durante a etapa pós-campo, as principais características observadas pelos estudantes para fazer a identificação das conchas encontradas foram a linha de crescimento, o umbo e a charneira, no caso das bivalves. Com relação às conchas de gastrópodes encontrados, as principais características analisadas foram a espiral, a volta corporal, a abertura e o canal sinfonal.

A classificação taxonômica de malacologia foi executada, por meio de fotografia, buscando, desta maneira, alterar minimamente o sambaqui. Para o exercício de taxonomia, adotamos o parâmetro de atingir a classificação de Gênero, não necessariamente identificarmos a espécie, utilizando manual de identificação de acordo com

Na etapa de campo, no primeiro momento, os grupos se prepararam para as atividades de coleta de dados, a partir de uma roda de conversa que antecedeu as atividades. Os estudantes utilizaram o aparelho celular para georreferenciar e fotografar os quadrantes que foram delimitados de acordo com o roteiro de campo, com vistas à caracterização do sambaqui como consta na Tabela 4.

Ainda na etapa de campo, é importante ressaltar que as técnicas utilizadas para a coleta de dados, foram, em sua maioria, desenvolvidas a partir do registro de imagens fotográficas e instrumentos que não alteraram as condições naturais em que se encontrou o sambaqui. A Figura 3 apresenta alguns registros dos momentos da aula de campo em que os grupos aplicavam e construíam conhecimentos, os quais, por sua vez, demonstraram que

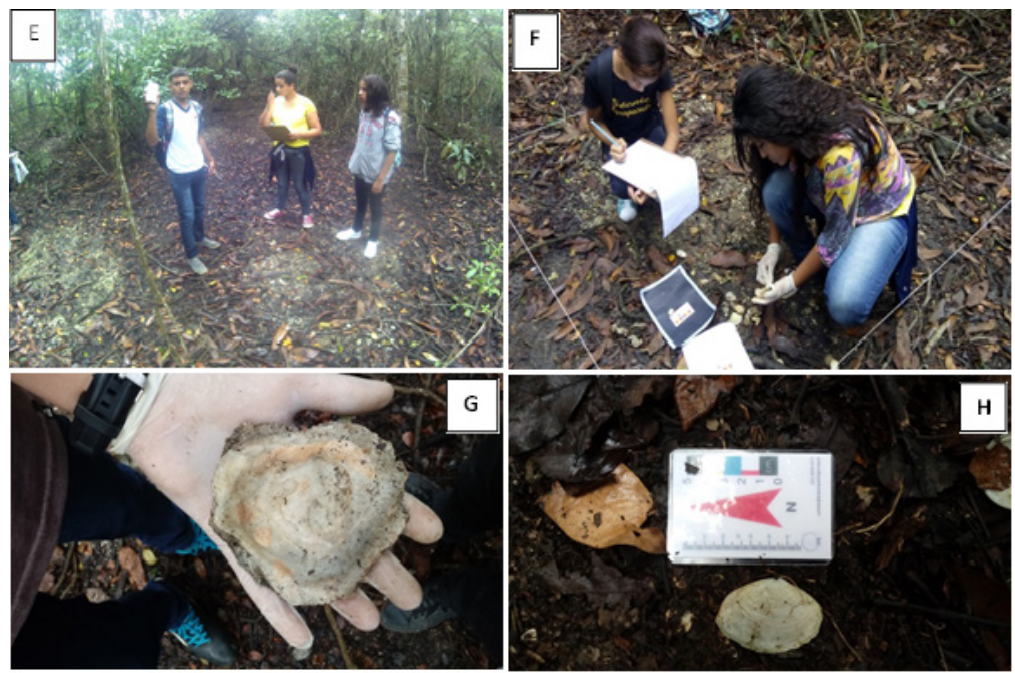

Figura 3. Momentos da aula de campo. E) Georreferenciamento do quadrante; F) Registros na área do quadrante; G) Valva de molusco; H) Valva referenciada com cartão escala. Fonte: 0 autor

\begin{tabular}{c|c|c|c|c|c}
\hline (C) Terrae Didat. & Campinas, SP & v.16 & $1-13$ & $\mathrm{e} 020047$ & 2020 \\
\hline
\end{tabular}


Tabela 4. Roteiro de campo Fonte: 0 autor

\begin{tabular}{l|l}
\hline Atividades & $\begin{array}{l}\text { Instrumentos e } \\
\text { material }\end{array}$ \\
\hline $\begin{array}{l}\text { Delimitar um quadrante de } 2 \mathrm{~m} \\
\text { X 2m observando a presença de } \\
\text { cocnhas. }\end{array}$ & $\begin{array}{l}\text { Trena, barbante e } \\
\text { palitos }\end{array}$ \\
\hline $\begin{array}{l}\text { Identificar o Norte geodésico do } \\
\text { quadrante. }\end{array}$ & Celular e bússola \\
\hline $\begin{array}{l}\text { Identificar a presença de } \\
\text { conchas de moluscos. }\end{array}$ & $\begin{array}{l}\text { Fotografia, cartão } \\
\text { de escala e prancha } \\
\text { de papel. }\end{array}$ \\
\hline $\begin{array}{l}\text { Identificar a presença de animais } \\
\text { viventes. }\end{array}$ & $\begin{array}{l}\text { Anotação no } \\
\text { diário de campo e } \\
\text { fotografias. }\end{array}$ \\
\hline $\begin{array}{l}\text { Identificar a presença de } \\
\text { vegetação. Descrever as suas } \\
\text { características, como raízes, } \\
\text { caule, folhas e altura. }\end{array}$ & $\begin{array}{l}\text { Anotação no } \\
\text { diário de campo e } \\
\text { fotografia. }\end{array}$ \\
\hline $\begin{array}{l}\text { Desenhar um croqui do } \\
\text { quadrante representando seus } \\
\text { aspectos bióticos e abióticos. }\end{array}$ & $\begin{array}{l}\text { Anotações no } \\
\text { diário de campo. }\end{array}$ \\
\hline $\begin{array}{l}\text { Descrever a superfície do solo } \\
\text { do quadrante }\end{array}$ & $\begin{array}{l}\text { Anotações no } \\
\text { diário de campo. }\end{array}$ \\
\hline $\begin{array}{l}\text { Identificar a presença da ação } \\
\text { humana. }\end{array}$ & $\begin{array}{l}\text { Anotações no } \\
\text { diário de campo e } \\
\text { fotografias. }\end{array}$ \\
\hline
\end{tabular}

ou nenhum outro artefato, natural ou antrópico encontrado nos quadrantes delimitados pelos grupos de estudantes para observação.

No que diz respeito à identificação dos avanços da alfabetização científica, no transcurso do desenvolvimento da pesquisa, consideramos pertinente adotar as três categorias, conforme Sasseron \& Carvalho (2008).

A análise dos dados se deu a partir da interpretação das relações das evidências estabelecidas entre a teoria e a prática desenvolvida, com vistas a identificar os indicadores de alfabetização científica, seus respectivos eixos estruturantes teóricos, os papeis didáticos da aula de campo e seus graus de influência nos objetivos, a partir dos pressupostos teóricos adotados de acordo com Compiani \& Carneiro (1993). Todas as etapas ocorreram sob a orientação do PP, o qual interveio quando necessário, permitindo que os alunos fizessem anotações e inferências no decorrer do processo e sempre orientando o trabalho em grupo, buscando traduzir os sentidos do trabalho em campo e do ambiente pesquisado.

\section{Resultados alcançados}

Apresentamos os resultados alcançados de acordo com as etapas propostas para o desenvolvimento da aula de campo. As etapas da aula de campo constituem-se formando um fio condutor indispensável para a consecução dos objetivos da pesquisa. Entretanto, antes de tratar das etapas pré-campo, campo e pós-campo, a aula de campo foi analisada de acordo com os pressupostos dos seus papéis didáticos, conforme Compiani \& Carneiro (1993).

Os parâmetros de categorização propostos nos permitem afirmar que a aula de campo desenvolvida nesta pesquisa pode ser caracterizada a partir dos seguintes papeis didáticos:

- Indutiva: característica que se fundamenta no fato de que a aula de campo apresentou diversas informações, as quais conduziram os participantes a elaborarem suas conclusões, como por exemplo, quando apontou que os sambaquieiros preferiam construir seus sambaquis sempre próximos a manguezais ou estuários, levando os alunos a perceberem que esta escolha derivava da presença de alimentos com mais abundância nestes locais. As atividades desenvolvidas na etapa pré-campo, cuja relação de ensino-aprendizagem foi centrada nos estudantes, ajudou os alunos na elaboração do estudo semidirigido que tratava sobre as características do sambaqui. Desta forma, predomina as lógicas da Ciência e do aprendiz, uma vez que os instrumentos de coleta de dados foram propostos pelo PP e as resoluções das atividades em campo foram desenvolvidas por meio das relações entre os estudantes, fato a partir do qual Compiani \& Carneiro (1993) caracterizam o desenvolvimento de exercício de habilidades, atitudes e valores por parte dos estudantes.

- Motivadora: por considerar que neste papel didático, ocorre a visão de ensino formativo, uma vez que a maioria dos estudantes, ou seja, quinze dos vinte e um estudantes participantes não haviam participado de uma aula de campo, pode-se afirmar que a aula motivou os alunos a visualizarem uma nova experiência. Ainda que considerado na relação de ensino-aprendizagem o estudo não-dirigido e que os modelos científicos aceitos podem variar sua aceitação, o estudante sendo o centro das atenções pode apresentar resultados mais satisfatórios. No caso desta pesquisa, os quatro grupos de alunos participaram com efetividade. Compiani \& Carneiro (1993) consideram os objetivos de reconhecer feições e fenômenos da natureza e formular dúvidas e questões como fundamentais para a formação do conhecimento, por parte do estudante. Estes fatos foram realizados quando 
os alunos caracterizaram o sambaqui e seu entorno e quando discutiram sobre a estratégia de conhecimento que seria mais adotada.

- Treinadora: considerando as informações da etapa pré-campo, a qual teve o objetivo de treinar os estudantes para a execução das atividades em campo, é possível reconhecer este papel didático na medida em que o estudo semidirigido ajudou os alunos a concretizarem os trabalhos de campo. Ao serem treinados para as tarefas que iriam realizar em campo, os alunos conseguiram intervir pedagogicamente com o ambiente, dele extraindo conhecimento. A lógica predominante permite a variação entre a Ciência e o aprendiz, sobre a qual Compiani \& Carneiro (1993) afirmam que os estudantes desenvolveram conhecimentos prévios para, posteriormente, aplicarem as suas diversas habilidades.

- Investigativa: considerando que neste papel didático a visão de ensino visa a conduzir o estudante a um processo formativo de pesquisa, em que ele é o centro na relação ensinoaprendizagem, é possível identificar esta característica na aula de campo desenvolvida. Este parâmetro de categorização é percebido na pesquisa, uma vez que os estudantes tiveram como objetivo específico a classificação taxonômica de conchas de moluscos das classes Bivalve e Gastrópoda. Para tanto, desenvolveram conhecimentos prévios, reconhecimento de feições e fenômenos da natureza, formularam dúvidas e questões, estruturaram sínteses e elaboraram conhecimentos ao desenvolverem o exercício de habilidades, atitudes e valores (Compiani \& Carneiro, 1993).

\section{As etapas da aula de campo}

Após discutir os papéis didáticos da aula de campo, podemos dizer que as etapas apresentam as relações entre os eixos estruturantes e os indicadores de alfabetização científica, uma vez que as características pedagógicas dos papeis didáticos constituem os sentidos e significados produzidos pelos estudantes em seus registros, durante todo o desenvolvimento das atividades.

A etapa pré-campo foi a etapa preparatória, tal qual consideramos fundamental para o desenvolvimento e os resultados da metodologia de ensino proposta. Consideramos que esta etapa foi potencialmente capaz de estimular os estudantes à pesquisa. Na etapa de campo, os grupos executaram em separado as atividades propostas com o subsídio de um roteiro de campo e das práticas desenvolvidas previamente em sala de aula. A etapa pós-campo foi a etapa da produção didática, com vistas aos objetivos da pesquisa e desenvolvida em sala de aula e no auditório da escola, onde os grupos, a partir das fotografias coletadas em campo, propuseram as classificações taxonômicas das conchas.

Apresentamos os indicadores de alfabetização científica em cada eixo estruturante, pois consideramos os três eixos necessários para que o cidadão conceba os pressupostos da alfabetização científica. O diálogo é necessário para o avanço da alfabetização científica, ao possibilitar que os estudantes de grupos diferentes compartilhem informações, questionamentos e conclusões.

Durante a etapa pré-campo, podemos perceber no eixo estruturante "Compreensão básica de termos, conhecimentos e conceitos científicos fundamentais", que o indicador de alfabetização científica "levantamento de hipóteses" ocorreu quando o estudante faz um questionamento ao PP, com relação à fisiologia do hominídeo apresentado no documentário e, quando a "classificação de informações" e o "raciocínio lógico" surgem na fala de um dos estudantes, dirigindo-se ao PP a partir de uma afirmação e um questionamento ao se referir ao gênero da espécie humana, demonstrando aquisição de conceitos científicos e habilidades cognitivas. As discussões estabelecidas neste episódio abrangem noções e mostram-nos preocupações em compreender de modo mais geral as relações existentes entre as espécies (Sasseron \& Carvalho, 2008).

$\mathrm{Na}$ etapa de campo, identificamos os indicadores de alfabetização científica a partir da "justificativa" do grupo em uma das atividades, a qual contém, por sua vez, o "raciocínio lógico" por parte de um dos estudantes ao confirmar a justificativa da colega durante a roda de conversa. Para Sasseron \& Carvalho (2008), estes indicadores apontam para a importância que reside na necessidade de compreender conceitos-chave como forma de poder entender as situações na resolução de problemas específicos ou peculiares ao dia-a-dia dos sujeitos. As relações estabelecidas entre os estudantes participantes na solução das atividades propostas, mostram que o ambiente escolar é fortalecido a partir das vivências com aulas em espaços não-formais.

O ambiente natural ou antrópico além dos muros escolares promovem significados relevantes no processo de ensino-aprendizagem escolar, uma vez que os estudantes trocam experiências vividas,

\begin{tabular}{c|c|c|c|c|c}
\hline (C) Terrae Didat. & Campinas, SP & v.16 & $1-13$ & $\mathrm{e} 020047$ & 2020 \\
\hline
\end{tabular}


como durante a etapa pós-campo, a qual apontamos o resultado da atividade de classificação taxonômica das conchas, onde os estudantes conseguiram encontrar onze gêneros de moluscos envolvendo as duas classes pesquisadas.

Com relação ao eixo estruturante "Compreensão da natureza das ciências e dos fatores éticos e políticos que circundam sua prática", a "seriação de informação" e o "levantamento de hipóteses" são os indicadores de alfabetização científica, os quais, a partir de relações dos momentos do documentário, na etapa pré-campo, o estudante observa a questão da subjetividade envolvendo as espécies do gênero Homo, uma vez que determinada espécie não enterrava seus mortos, mas, outra espécie, o faziam. Ao observar que os sambaquis poderiam ter demorado pouco tempo, ou não, para serem construídos, os estudantes demonstraram raciocínio lógico durante o diálogo.

$\mathrm{Na}$ etapa de campo, os indicadores de alfabetização científica, "justificativa", "seriação de informação" e "raciocínio lógico", uma vez que o grupo fez sua justificativa conforme proposta nas atividades, elencando informações e apresentando o pensamento critico. Desta forma, o comentário da estudante com relação ao estado de degradação da passarela de acesso promove o pensamento crítico que produz o desenvolvimento da reflexão em condições dialéticas, as quais consideram o mundo e a ação, intimamente solidários (Freire, 2011). Para discutir o eixo estruturante de alfabetização científica "Compreensão e entendimento das relações exis- tentes entre ciência, tecnologia, sociedade e meio-ambiente", os estudantes com base em afirmações de "justificativa", de "classificação de informações", de "raciocínio lógico" e de "levantamento de hipóteses", apontam indicadores para o avanço no processo de alfabetização científica, uma vez que em situações da palestra, os estudantes se viram envolvidos nos tempos pretéritos. Durante a palestra de educação patrimonial ocorrida na etapa pré-campo, em um diálogo com o PP e o historiador, uma estudante, após ser questionada pelo PP, concorda, com base no diálogo, que, no futuro, escavações arqueológicas poderão demonstrar que o celular representará a tecnologia da atualidade nos tempos futuros. Na etapa de campo, os indicadores de alfabetização científica, "levantamento de hipóteses", "raciocínio lógico" e "classificação de informações" foram elencados por meio da observação das atividades pelos grupos de estudantes em conjunto, como também, nas falas contidas nos diálogos entre os estudantes, com vistas à resolução dos problemas apresentados.

A Tabela 5 apresenta os dados coletados nas etapas de pré-campo e campo, com o objetivo de ilustrar os indicadores predominantes correspondentes aos diálogos citados.

Para finalizar a abordagem das etapas da aula de campo, o eixo estruturante "Compreensão e entendimento das relações existentes entre ciência, tecnologia, sociedade e meio-ambiente", com relação ao pós-campo, está estritamente ligado ao uso das tecnologias para fazer ciências, com vistas

Tabela 5. Registros coletados e indicadores de alfabetização científica. Fonte: Adaptado de Sasseron \& Carvalho (2008)

\begin{tabular}{|c|c|c|}
\hline $\begin{array}{l}\text { Etapas da aula } \\
\text { de campo }\end{array}$ & $\begin{array}{l}\text { Indicadores de alfabetização } \\
\text { científica }\end{array}$ & Registros \\
\hline \multirow[b]{2}{*}{ Pré-campo } & -Levantamento de hipóteses & $\begin{array}{l}\text { Professor, porque aqueles primeiros homens pré-históricos ficavam babando } \\
\text { quando comia o resto de carne do tigre? }\end{array}$ \\
\hline & $\begin{array}{l}\text {-Classificação de informações } \\
\text {-Raciocínio lógico } \\
\text {-Levantamento de hipóteses }\end{array}$ & $\begin{array}{l}\text { Professor! Esse gênero que a "gente humano" é classificado, os hominídeos... } \\
\text { a gente então era no passado, um bicho selvagem igual aos outros animais } \\
\text { da cadeia alimentar da natureza, na época? }\end{array}$ \\
\hline Campo & $\begin{array}{l}\text {-Justificativa } \\
\text {-Raciocínio lógico }\end{array}$ & $\begin{array}{l}\text { Grupo (1): "A gente escolheu fotografar a placa porque é uma informação } \\
\text { sobre o lugar que a gente vai estudar". } \\
\text { "Isso! Nós decidimos essa, porque vai ajudar no relatório". }\end{array}$ \\
\hline \multirow{3}{*}{ Pré-campo } & \multirow{3}{*}{$\begin{array}{l}\text { - Seriação de informação } \\
\text { - Raciocínio lógico } \\
\text { - Levantamento de hipóteses }\end{array}$} & $\begin{array}{l}\text { Eu vi professor, que eles enterram o morto, só quando aparece aqueles } \\
\text { homens do gelo. Aqueles que dominaram o fogo não enterrava, mas eles } \\
\text { também não comiam o morto... eu achei na hora que eles fossem comer o } \\
\text { corpo. }\end{array}$ \\
\hline & & $\begin{array}{l}\text { Pra ficar daquele tamanho deve ter demorado muito tempo. } \\
\text { Pode ter demorado poucos anos, se eles fossem uma população muito } \\
\text { grande! }\end{array}$ \\
\hline & & Então será que pode ter gente enterrada lá no sambaqui? \\
\hline \multirow{3}{*}{ Campo } & \multirow{3}{*}{$\begin{array}{l}\text { - Seriação de informação } \\
\text { - Raciocínio lógico } \\
\text { - Levantamento de hipóteses }\end{array}$} & $\begin{array}{l}\text { Tenho uma dúvida aqui pessoal! Esse duzentos é que é os dois metros do } \\
\text { quadrante? }\end{array}$ \\
\hline & & $\begin{array}{l}\text { Todos os grupos delimitaram os quadrantes de estudo utilizando } \\
\text { técnicas simples de medição. }\end{array}$ \\
\hline & & $\begin{array}{l}\text { Todos os grupos conseguiram executar a localização geográfica do } \\
\text { quadrante utilizando o GPS do aparelho celular. }\end{array}$ \\
\hline
\end{tabular}


ao avanço da alfabetização científica no ensino de ciência do ensino fundamental. Para Sasseron \& Carvalho (2011), a importância disso reside em que se torna possível planejar aulas em que os estudantes exerçam ações que se aproximam do fazer científico quando estão aprendendo conteúdos científicos.

Com base no manual de identificação de conchas de sambaquis brasileiros, Souza, et al. (2011) e a utilização de instrumentos eletrônicos, como notebook e projetor de imagem, as principais características foram observadas pelos estudantes para fazer a identificação das conchas encontradas.

O resultado dos exercícios de taxonomia está descrito nas Figuras 4 a 7. A sequência corresponde às imagens da seleção das conchas propostas pelos grupos.

Os diálogos estabelecidos nesta etapa mostraram que os efeitos da aula de campo foram eficientes para o aprendizado dos estudantes, pois as atividades foram relacionadas às competências e habilidades, as quais estão ligadas ao trabalho empírico. Os indicadores observados nesta etapa corroboram Chassot (2016), uma vez que o processo de alfabetização científica desenvolvido está intrinsecamente relacionado com os currículos escolares de Ciências que, por sua vez, têm buscado apoio na contextualização social destes saberes, destacando o papel da ciência de maneira inter-relacionada com a tecnologia e a sociedade, uma vez que foram utilizadas tecnologias nas atividades desenvolvidas.

\section{Considerações Finais}

A pesquisa permitiu tecer algumas considerações acerca do desenvolvimento das etapas, as quais apresentam evidências importantes para a discussão proposta acerca do potencial dos sambaquis como espaços de educação não-formal para aulas de campo. Com relação aos resultados da produção didática, a totalidade dos dados coletados pelos estudantes durante todas as etapas da pesquisa conseguiu caracterizar o sambaqui estudado de acordo com os aspectos propostos. A etapa pré-campo é considerada fundamental para o desenvolvimento metodológico da aula de campo, tendo em vista sua instrumentalização em sala de aula, como apresentado
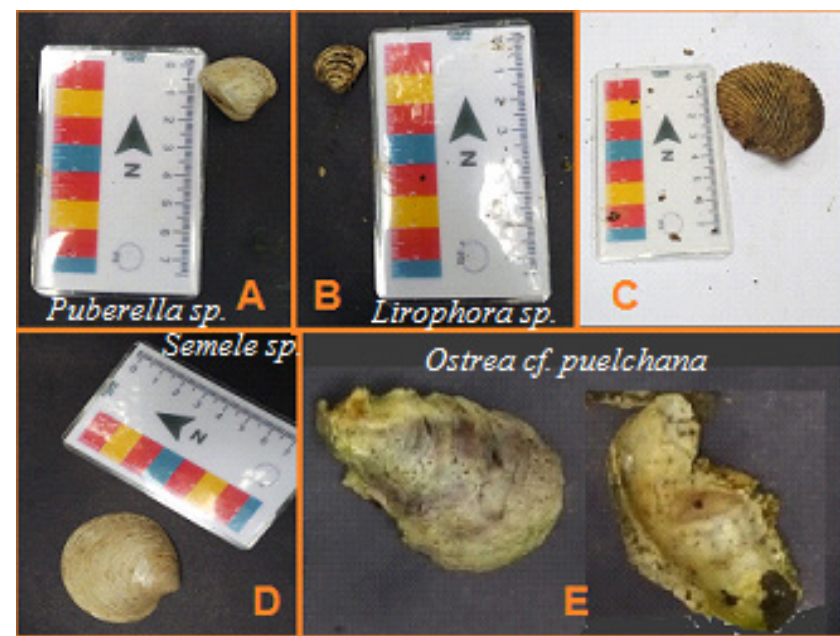

Ostrea of. puelchana

Figura 4. Taxonomia das conchas do grupo (1). Fonte: 0 autor

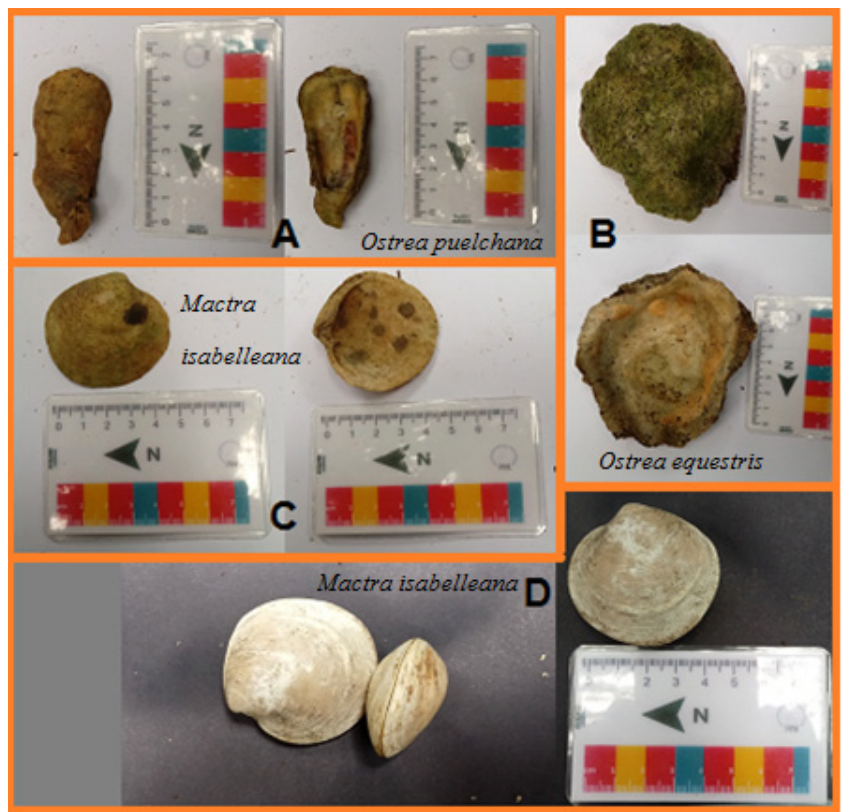

Figura 5. Taxonomia das conchas do grupo (2). Fonte: 0 autor

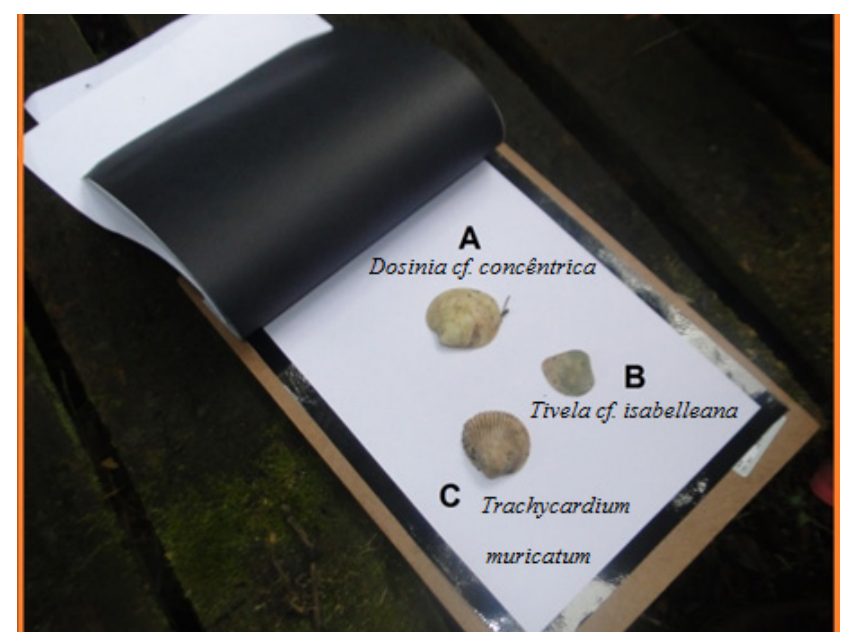

Figura 6. Taxonomia das conchas do grupo (3). Fonte: 0 autor 


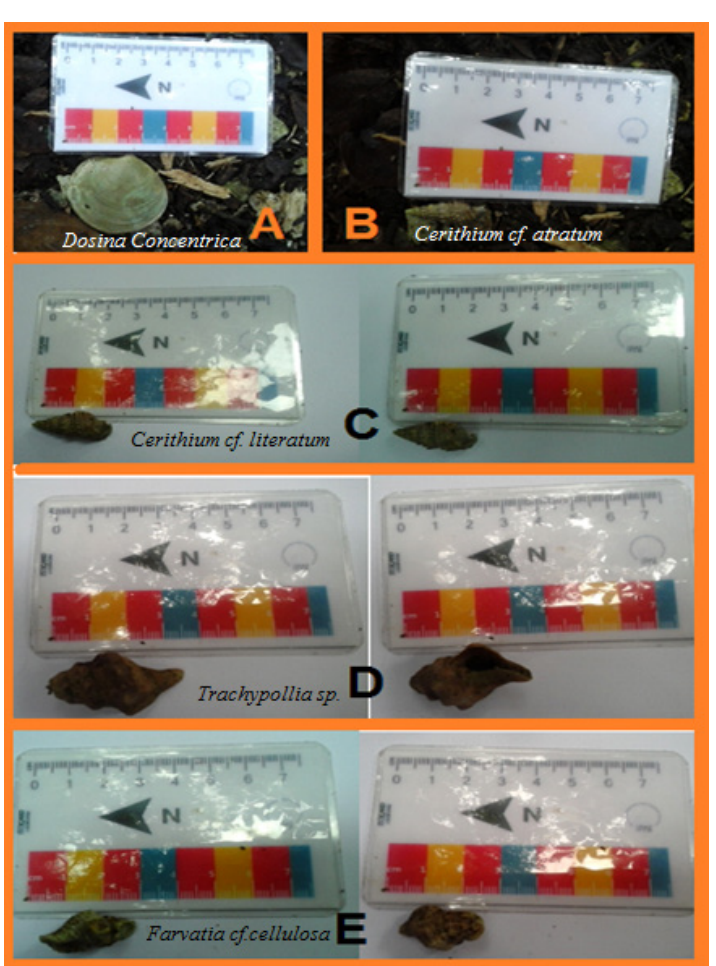

Figura 7. Taxonomia das conchas do grupo (4). Fonte: 0 autor

no diálogo transcrito dos resultados da etapa. Em "campo", embora a atividade de registro fotográfico das conchas não tenha conseguido revelar todas as posições necessárias para a identificação dos moluscos, as imagens conseguidas puderam caracterizar alguns aspectos importantes do sambaqui. A etapa pós-campo apresenta consideráveis dados sobre a diversidade biológica dos moluscos do sambaqui estudado. As conchas encontradas permitem afirmar que havia pelo menos onze gêneros entre os bivalves e gastrópodes.

Assim, quando organizamos nossa prática a partir dessas atividades, conseguimos atingir o objetivo de desenvolver uma aula de campo para o ensino de tópicos de Ciências, entre os quais abordagem de temas malacológicos. Os estudantes foram incentivados a proceder em campo como cientistas no trabalho de coleta de amostras e sua análise, acompanhados de um manual ordenador do trabalho, Souza, et al. (2011).

Quanto aos papeis didáticos, a aula de campo evidenciou a destreza dos estudantes de exercitar habilidades, como adquirir ou justificar conhecimentos teóricos, coleta de material e análise em laboratório; caracteriza-se assim como indutiva, motivadora, treinadora e investigativa. Segundo Compiani \& Carneiro (1993), os papeis didáti- cos assumem algum significado para o alcance de objetivos didáticos dentro do processo de ensino aprendizagem que são decididos de maneira deliberada, ou não.

As potencialidades do sambaqui para o ensino de Ciências, com vistas à alfabetização científica, ficam evidentes quando os estudantes desenvolveram suas observações no diálogo acerca dos fatores naturais e culturais constituintes do próprio sambaqui. Nas falas dos estudantes ocorrem percepções relacionando o tempo presente e os tempos pretéritos. Em caso de algumas pretensões não atingidas, embora demonstrado o alcance dos objetivos da proposta da pesquisa, ao menos um arcabouço metodológico e temático deixaremos para os professores-pesquisadores, os quais poderão ser proveitosos tanto para discussão e análise quanto para incentivo a estudos posteriores, visto que os sítios arqueológicos do tipo sambaqui são espaços potenciais para diversas abordagens.

\section{Agradecimentos}

O autor agradece a participação de Amanda Lira de Souza, Ana Christina Souza, Ana Lívia Baiense, Ana Paula J. Rorigues, Flávia de Souza Benigno, Geane Rodrigues dos Santos, Ítaro Maia Costa, Janiele Marques Areas, José Armando da Silva, Júlio Pires Roco, Karlos Pinto de Almeida, Luana de Oliveira, Luis Felipe de Oliveira, Marcos Lucas Mendonça, Mariana dos Anjos Silva, Meirielly Cipriano de Assis, Ramon Almeida Santos, Samuel Pinto de Almeida, Saulo Cardoso Martins, Victor José Lírio, Yuri Clemente da Silva.

\section{Referências}

Cardoso, J. M. Renata E. da S. Bruna C. Z. (2019). Sambaquis : uma história antes do Brasil: guia didático. São Paulo: MAE/USP, 33 p. ISBN: 978-85-6098465-7 10.11606/9788560984657.

Compiani, M.; Carneiro, C. D. R. (1993). Os papeis didáticos das excursões geológicas. Enseñanza de las Ciencias de la Tierra, 1 (2). 90-98. Madrid, Asociación Española para la Enseñanza de las Ciencias de la Tierra (AEPECT). URL: http://www.raco. cat/index.php/ECT/article/view/88098/140821. Acesso 18.08.2019.

Chassot, A. (2016). Alfabetização científica: questões e desafios para a educação. Ijuí: Unijuí.

Chassot, A. (2003). Alfabetização científica: uma possibilidade para a inclusão social. Revista Brasileira de Educação, 22, 89-100. doi: 10.1590/S141324782003000100009.

Blasis, P. A. D. de, Kneip, A., Scheel-Ybert, R., Giannini, P. C. F., \& Gaspar, M. D. (2007). Sambaquis e 
paisagem: dinâmica natural e arqueologia regional no litoral do sul do Brasil. Arqueología Suramericana = Arqueologia Sul-Americana, 3(1), 29- 61.

Durant, J. (2005). O que é alfabetização científica? Terra incógnita: a interface entre Ciência e público, 5(1), 14-26.

Freire, P. (1987). Educação e Mudança. Rio de Janeiro: Paz e Terra, 46p.

Freire, P. (2011). Pedagogia da autonomia: saberes necessários à prática educativa.28. ed. São Paulo: Paz e Terra, 148 p.

Gaspar, M. D. (2000). Sambaqui: arqueologia do litoral brasileiro. Rio de Janeiro: Jorge Zahar Editor. (Col. Descobrindo o Brasil).

Jacobucci, D. F. C. (2008). Contribuições dos espaços não-formais de educação para a formação da cultura científica. Uberlândia, Em extensão, 7(1), 55-66.

Lüdke, M. André, M. E. D. (1986). Pesquisa em educação: abordagens qualitativas. São Paulo: EPU.

Sasseron, L. H., Carvalho, A. M. P. (2011). Alfabeti- zação Científica: uma revisão bibliográfica. São Paulo, Investigações em Ensino de Ciências, 16(1), 5977.

Sasseron, L. H., Carvalho, A. M. P. (2008). Almejando a alfabetização científica no ensino fundamental: a proposição e a procura de indicadores do processo. São Paulo, Investigações em Ensino de Ciências, 13(1), 333-352.

Scheel-Ybert, R. (1999). Paleoambiente e paleoetnologia de populações sambaquieiras do sudeste do Estado do Rio de Janeiro. São Paulo, Revista do Museu de Arqueologia e Etnologia, 9. p. 43-59. URL: http://www.revistas.usp.br/revmae/article/ view/109341/107829. Acesso 05.05.2017.

Scheel-Ybert, R. (2001). Man and vegetation in the Southeastern Brazil during the Late Holocene. Journal of Archaeological Science, 28, 471-480.

Souza, R. C. C. L. (2011). Conchas marinhas de sambaquis do Brasil. Rio de Janeiro: Technical Books. 